American Journal of Agricultural and Biological Sciences 7 (2): 180-185, 2012

ISSN 1557-4989

(C) 2012 Science Publications

\title{
Validation of the Ceres-Wheat for Prediction of Wheat Varieties in Irrigation and Terminal Drought Stress
}

\author{
${ }^{1}$ Farzad Paknejad, ${ }^{2}$ Fatemeh Majidi Fakhr and ${ }^{3}$ Seied Mehdi Mirtaheri \\ ${ }^{1}$ Department of Agronomy, Agriculture Research Center, \\ Karaj Branch, Islamic Azad University, Karaj, Iran \\ ${ }^{2}$ Department of Agronomy, Karaj Branch, Islamic Azad University, Karaj, Iran \\ ${ }^{3}$ Department of Agronomy, Islamic Azad University Roudehen Branch, Roudehen, Iran
}

\begin{abstract}
Problem statement: Crop growth models have many potential uses for crop managements. Approach: In order to evaluation of CERES-Wheat model on five varieties of winter wheat in Karaj weather condition in Full Irrigation (FI) and Stop Irrigation (SI) after flowering until final growth stage an experiment conducted in shape of split plot in based on randomize complete block design with four replicate in research field Islamic Azad university of Karaj branch in 2009-2010. Two irrigation levels located in main plot and cultivars as sub plot. In this study simulation of some traits such as Grain Yield (GY), Biomass (B) and Leaf Area Index (LAI) was evaluated by use of CERES-Wheat model. Results: According to results, model was successful in simulation of traits whole under two irrigation treatments. Rate of coefficient of correlation $\left(\mathrm{R}^{2}\right)$ was low in regression curve of measured versus simulated for traits of LAI. Model simulated GY with high vigor for both irrigation conditions. Variation dimension of $\mathrm{R}^{2}$ in FI and SI obtained 0.8089-0.8097 and 0.8087-0.9504, respectively. Variation dimension of Wilmot coefficient (d) FI and SI was 0.65-0.74 and 0.58-0.74, respectively. Simulation precise in SI was lower than FI. We could after evaluation and calibration model by means of experimental replication and reduce of Root Mean Square Error (RMSE) as a result used for research objective management programming in Karaj area. Conclusion: The results of CERESWheat model assessment in this research indicated that this model in full irrigation and discontinuing the irrigation after flowering stage have appropriate and good accurate, simulation of seed yield and biomass but has simulated the leaf area index well only in full irrigation conditions.
\end{abstract}

Key words: Stop Irrigation (SI), Full Irrigation (FI), Grain Yield (GY), Leaf Area Index (LAI), Root Mean Square Error (RMSE), Water Use Efficiency (WUE)

\section{INTRODUCTION}

Water stress due to drought and salinity is probably the most significant abiotic factor limiting plant and also crop growth and development (AlTaisan, 2010). Dryness is one of the most important factors which limit the production of crops, including wheat in the world and Iran (Ahmadizadeh et al., 2012). Drought stress can reduce grain yield, therefore, it has been estimated that average yield loss of $17-70 \%$ in grain yield is due to drought stress (Ahmadizadeh et al., 2011). Simulation modeling of several proposed cropping systems in a few experimental locations can provide more useful, quicker and less costly alternative approach. For the past few decades researchers have developed dynamics crops-growth simulation models (Kiani, 2002). In the arid and semiarid zones, shortage of water is ever one of the main limitations for agricultural development and therefore promotion of
Water Use Efficiency (WUE) in these zones is very important. Simulation models can be useful when appropriately applied, as they allow study of outcomes over many seasons in parallel with minimal computing time and with control over unwanted factors. Considering the capability of CERES-wheat for determination of quantitative effects of different climatic, environmental and managerial parameters on production of wheat, through choosing different strategies such as assessment of producing different varieties, the different plantin dates, reviewing the amount and time of nitrogen consumption and simulation may evaluate the effects of these factors with the longterm meteorological data, growth, reproduction and yield of wheat in the regional and national levels (Boote et al., 2001).

After a thorough evaluation of CSM CROP SIM CERES-Wheat, the model was able to reasonably quantify wheat development, growth and yield

Corresponding Author: Fatemeh Majidi Fakhr, Department of Agronomy, Karaj Branch, Islamic Azad University, Karaj, Iran 
responses to within-season variability in plant population and nitrogen application rate and to seasonal variation in weather and management practices (Thorp et al., 2010). Knorzer et al. (2011) reported that integrating a simple shading algorithm into CSMCERES seemed to be promising as wheat and maize grain and dry matter yield could be simulated adequately in both the intercropping and the monocropping system.

Andarzian et al. (2008) in a study with wheatPot model that were conducted in different locations across the Khouzestan-Iran, province over the 2003-2004 and 2004-2005 growing seasons. According to their results of the model evaluation under the environmental conditions of Khouzestan province showed that the model had predicted yield potential from $-5 \%$ to $+19 \%$ of the measured yield .

This study has been implemented with the objective of analyzing the CERES-Wheat model for simulation of growth, reproduction and yield of wheat in full irrigation and stop irrigation from flowering stage up to final growth stage in five varieties of winter wheat in the climatic conditions of Karaj.

\section{MATERIALS AND METHODS}

In order to evaluation of CERES-Wheat model on five varieties of winter wheat (Gaspard, Toos, Zarin, Saison and Pishgam) under Karaj weather condition in Full Irrigation (FI) and Stop Irrigation (SI) after flowering untill final growth stage, an experiment was conducted in the form of split plot based on completely randomized blocks design with four replications in research field Islamic Azad university of Karaj branch in 2009-2010. Before planting, $400 \mathrm{~kg} \mathrm{~N} \mathrm{ha}^{-1}$ were applied (1/3 before planting and $2 / 3$ in stem elongation stage applied), based on soil analysis at 0-30 depth.

For execution of CERES-Wheat model, two categories of data are required:

- Measured data which are the same observed data in the field

- Simulated data that are provided via CERESWheat model aiding input data. Finally upon comparing the observed and simulated data, the model capability for case simulation is analyzed.

During the growth season, considering the required input data for execution of the model, parameters such as plant height, leaf numbers, leaf area index and accumulation of leaf's dry matter was measured via six stages.
Also, for introducing the required special genetic characteristics for the varieties (wheat) quantitatively to the model, after collecting some genetic characteristics from seed an plant improvement Institute of Karaj and measuring during the growth season, GENCALC software has been used.

The data and information required for execution of CERES-Wheat model are as follows.

Managerial information: Including specifications of test plots, plant spacing, depth of planting, seed and seedling density, test execution method, introduction of experiment treatments, introduction of varieties, irrigation method and declaration of amount and time of irrigation, fertilizer using method and its amount, dates of planting and harvesting, soil structure and texture.

Soil information: Including physical and chemical characteristics of soil, soil texture, soil density, percentage of organics matter, available nitrogen, phosphorus and potassium, soil $\mathrm{PH}$ and soil electrical conductivity.

Measured experimental data: the data related to the duration of test period and then the data related to the final harvest date that each one has distinct files.

Weather information including the most important factors effective on the plant growth including: the maximum and minimum daily temperature (centigrade), daily raining (millimeter) and daily sunny hours or solar radiation.

The treatment of stopping irrigation has been applied after $50 \%$ pollination stage of the plants of each plot for all varieties on 29.04.2010. The final harvest has been provided on 07.06.2010 from three middle lines of each plot for 3 meters after deleting 0.5 meters of the line sides. SAS program was used for statistical analysis of data conducted and excel program for drafting the diagrams.

For comparing the simulated data to the data gained from field experiments, assessment indices, Willmott (1982) agreement index (d) and coefficient of correlation $\left(\mathrm{R}^{2}\right)$ resulted from linear regression analysis and 1:1 line was used Eq. 1 (Eitzinger et al., 2003):

$\mathrm{d}=\frac{\sum_{\mathrm{i}=1}^{\mathrm{n}}\left(\mathrm{p}_{\mathrm{i}} \mathrm{o}_{\mathrm{i}}\right)^{2}}{\sum\left(\mid \mathrm{p}_{\mathrm{i}}-\mathrm{o}_{\text {iavg }}\right)+\left(\left|\mathrm{o}_{\mathrm{i}}-\mathrm{o}_{\text {iavg }}\right|\right)^{2}}$

which, $\mathrm{p}_{\mathrm{i}}$ and $\mathrm{o}_{\mathrm{i}}$ are respectively the predicted and measured amounts, $\mathrm{n}$ the number of observations and $\mathrm{O}_{\text {iavg }}$ the average of observed amounts. 
Whatever the amounts of $\mathrm{d}$ gained by model are closer to one means that the model was more successful in simulation and could predict the trait with lower difference to the observed amounts. According to the reports of some modelers, the statistical results of simulation with the $\mathrm{d}$ amounts over 0.60 for 6 samples indicates the acceptable capability of the model for simulation and whatever the amount of $\mathrm{R}^{2}$ resulted from analysis of linear regression of the functions and line $1: 1$ are closer to 1 , indicates the high correlation between simulated and observed amounts and means the model has described the trait by simulation better (Reza et al., 2005).

\section{RESULTS}

Simulation of seed yield: The comparison of correlation (Table 1) of measured and simulated seed yield for the wheat varieties in full-irrigation and stopping irrigation conditions indicates the high capability of the model for yield simulation in these conditions in Karaj. Upon reviewing the coefficient of correlation $\left(\mathrm{R}^{2}\right)$ resulted from linear regression analysis of the functions between the measured and simulated amounts of seed yield of wheat varieties, coefficient of correlation in full-irrigation and discontinuing of irrigation are respectively within the range of 0.8089-0.8097 and 0.8087-0.9504 which indicates the appropriateness of the model for simulation of seed yield in both conditions of irrigation. The trend of simulated variation of seed yield in full-irrigation and stop irrigation for wheat varieties by CERES-Wheat model in Karaj, as per Fig. 1 and variation range of $\mathrm{d}$ coefficient in different varieties are respectively within the range of $0.65-0.74$ and 0.58-0.74 and indicates the model was successful in predicting the seed yield variation trend in both irrigation conditions.

As it is observed in Fig. 1, in case of drought stress to the normal irrigation for all wheat varieties, the yield is reduced and the model could show appropriately the yield loss in stress conditions compare with the normal condition.

Biomass simulation: Upon comparing the correlation (ratio 1:1) of measured and simulated biomass in wheat varieties in full-irrigation and stopping irrigation conditions, it is concluded that the model is very capable for simulation of this trait in both conditions (Table 2). Upon analyzing the coefficient of correlation $\left(\mathrm{R}^{2}\right)$ resulted from analysis of function' linear regression within the amounts of measured and simulated biomass of wheat varieties, the coefficient of correlation in full-irrigation and stopping irrigation conditions is respectively within $0.8990-0.9461$ and $0.8910-0.9416$ and indicates the appropriateness of the model for biomass simulation in both irrigation conditions (Table 2). The trend of simulated biomass variations in full-irrigation and stopping irrigation conditions for wheat varieties aiding CERES-Wheat model in Karaj, considering the Fig. 2 and variations range of $\mathrm{d}$ coefficient in different varieties are respectively within the range of 0.92-0.95 and 0.94-0.95 that indicates the model success for predicting the trend of biomass variations in both irrigation conditions (Fig. 2). Also based on Fig. 2 the model simulated biomass variations trend in both conditions well.

Simulation of Leaf is Index (LAI): According to the diagrams of the measured and simulated correlation of leaf area index of varieties in full-irrigation conditions indicates the high capability of model for this trait simulation (Table 3).

Table 1: Simulated and measured grain yield of the winter wheat (1:1 line)

\begin{tabular}{|c|c|c|c|c|}
\hline \multirow[b]{2}{*}{ Varieties } & \multicolumn{2}{|c|}{ Normal irrigation } & \multicolumn{2}{|l|}{ Droutht strees } \\
\hline & $Y=X$ & $\mathrm{R}^{2}$ & $Y=X$ & $\mathrm{R}^{2}$ \\
\hline Toos & $\mathrm{Y}=0.6827 \mathrm{X}$ & 0.8091 & $\mathrm{Y}=0.5565 \mathrm{X}$ & 0.8087 \\
\hline Gaspard & $Y=0.8840 X$ & 0.8097 & $Y=0.9376 X$ & 0.8095 \\
\hline Zarrin & $Y=0.9524 X$ & 0.8089 & $Y=0.6989 X$ & 0.8088 \\
\hline Saison & $\mathrm{Y}=0.8431 \mathrm{X}$ & 0.8096 & $\mathrm{Y}=0.3090 \mathrm{X}$ & 0.9504 \\
\hline Pishgam & $\mathrm{Y}=0.8380 \mathrm{X}$ & 0.8097 & $Y=0.6994 X$ & 0.8093 \\
\hline
\end{tabular}

Table 2: Simulated and measured biomass of the winter wheat (1:1 line)

\begin{tabular}{lllll}
\hline & \multicolumn{2}{l}{ Normal irrigation } & \multicolumn{2}{l}{ Droutht strees } \\
Varieties & $\mathrm{Y}=\mathrm{X}$ & $\mathrm{R}^{2}$ & $\mathrm{Y}=\mathrm{X}$ & $\mathrm{R}^{2}$ \\
\hline Toos & $\mathrm{Y}=1.112 \mathrm{X}$ & 0.9284 & $\mathrm{Y}=0.9308 \mathrm{X}$ & 0.9100 \\
Gaspard & $\mathrm{Y}=1.095 \mathrm{X}$ & 0.8990 & $\mathrm{Y}=1.0062 \mathrm{X}$ & 0.8910 \\
Zarrin & $\mathrm{Y}=1.0771 \mathrm{X}$ & 0.9461 & $\mathrm{Y}=0.8319 \mathrm{X}$ & 0.9100 \\
Saison & $\mathrm{Y}=0.975 \mathrm{X}$ & 0.9132 & $\mathrm{Y}=0.9558 \mathrm{X}$ & 0.8963 \\
Pishgam & $\mathrm{Y}=0.995 \mathrm{X}$ & 0.9188 & $\mathrm{Y}=0.9043 \mathrm{X}$ & 0.9416 \\
\hline
\end{tabular}

Table 3: Simulated and measured leaf area index (LAI) of the winter wheat ( $1: 1$ line)

\begin{tabular}{|c|c|c|c|c|}
\hline \multirow[b]{2}{*}{ Varieties } & \multicolumn{2}{|c|}{ Normal irrigation } & \multicolumn{2}{|l|}{ Droutht strees } \\
\hline & $Y=X$ & $\mathrm{R}^{2}$ & $Y=X$ & $\mathrm{R}^{2}$ \\
\hline Toos & $\mathrm{Y}=1.0193 \mathrm{X}$ & 0.8899 & $\mathrm{Y}=0.7274 \mathrm{X}$ & 0.5557 \\
\hline Gaspard & $\mathrm{Y}=1.1931 \mathrm{X}$ & 0.8091 & $Y=1.8594 X$ & 0.6652 \\
\hline Zarrin & $Y=1.03118 X$ & 0.6969 & $\mathrm{Y}=0.8201 \mathrm{X}$ & 0.4404 \\
\hline Saison & $\mathrm{Y}=0.0817 \mathrm{X}$ & 0.9062 & $Y=0.9524 X$ & 0.7713 \\
\hline Pishgam & $Y=0.1158 X$ & 0.7621 & $Y=0.8677 X$ & 0.4340 \\
\hline
\end{tabular}


Am. J. Agri. \& Biol. Sci., 7 (2): 180-185, 2012
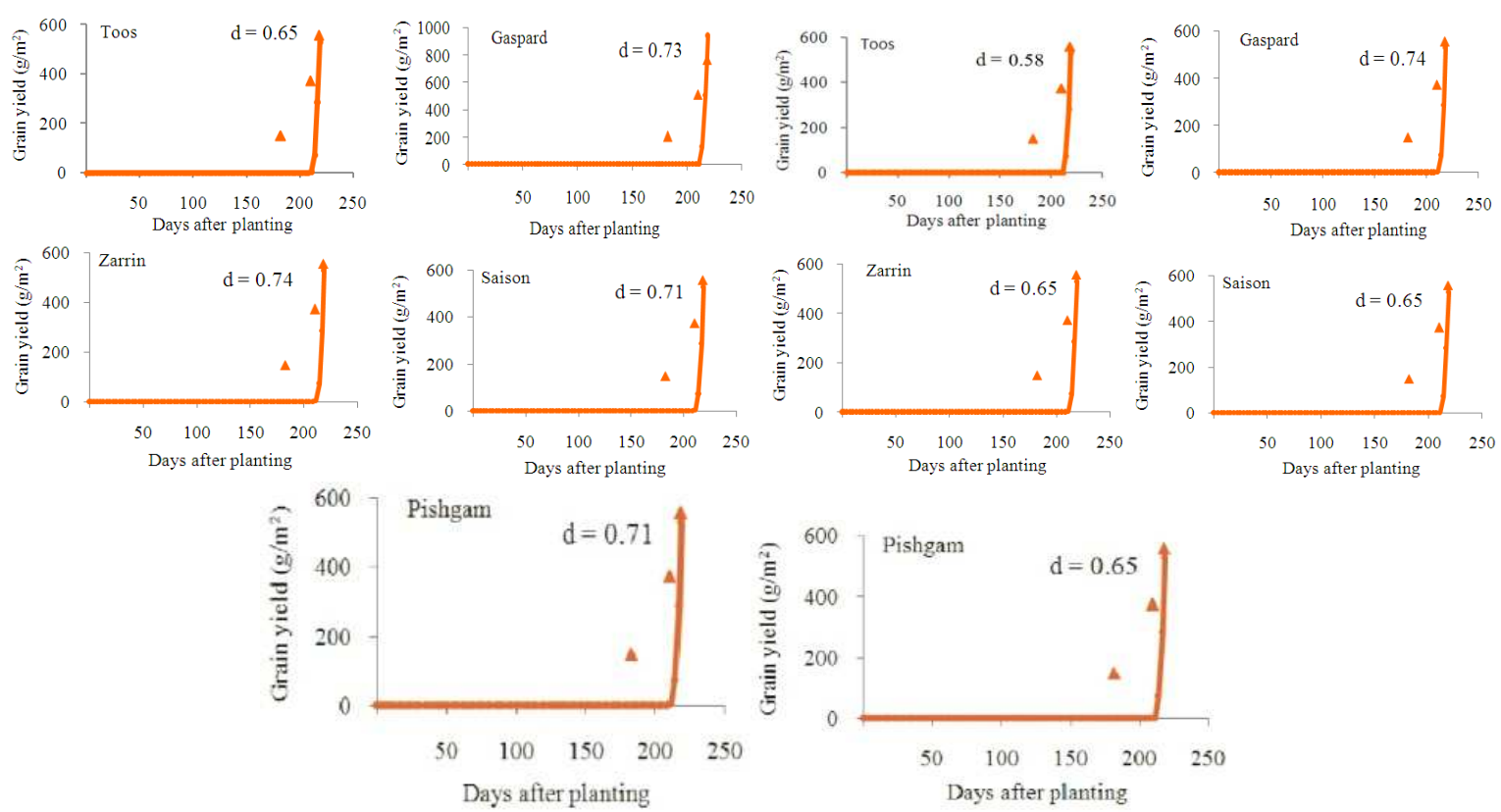

Fig. 1: Observed Grain yield $\left(\mathrm{g} / \mathrm{m}^{2}\right)(\Delta)$ and predicted with the model ( - ) in normal irrigation (left side) and drought stress (right side)
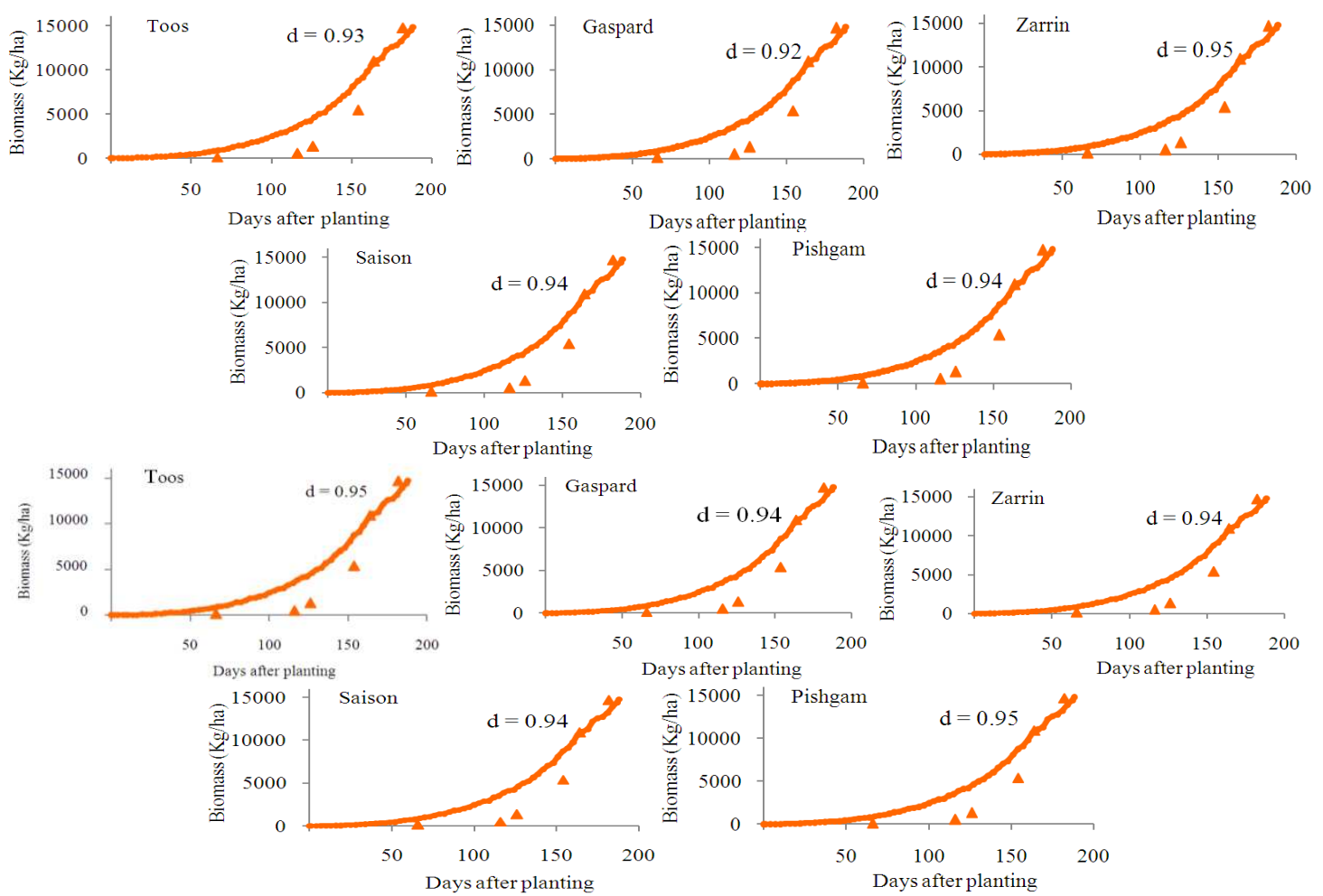

Fig. 2: Observed biomass (kg/ha) ( $\triangle$ ) and predicted with the model ( - ) in normal irrigation (up 5 figures) and drought stress (down 5 figures) 
Am. J. Agri. \& Biol. Sci., 7 (2): 180-185, 2012
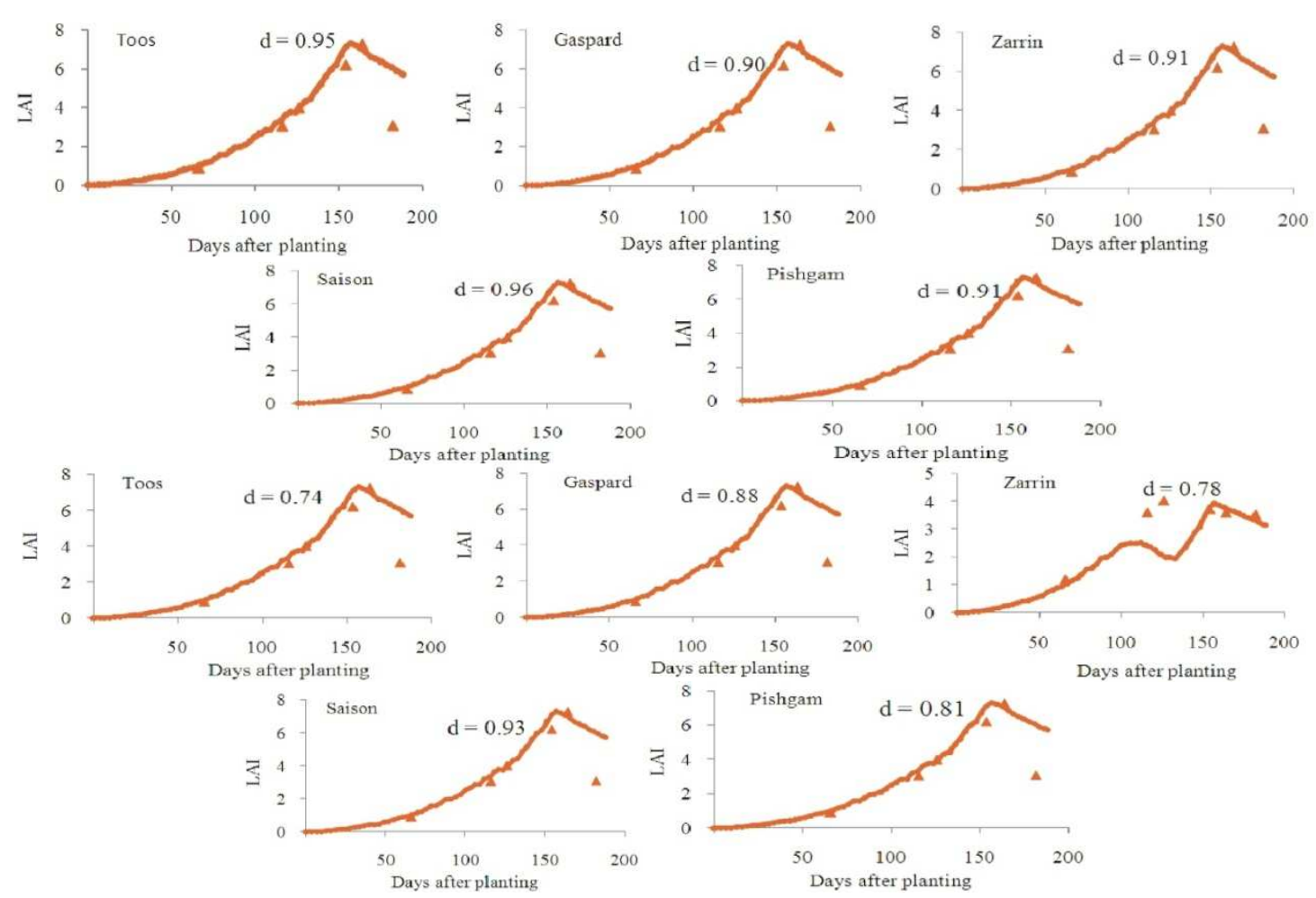

Fig. 3: Observed leaf are index (LAI) $(\Delta)$ and predicted with the model ( - ) in normal irrigation (up 5 figures) and drought stress (down 5 figures)

The coefficient of correlation $\left(\mathrm{R}^{2}\right)$ resulted from analysis of linear regression of varieties' measurement and simulation functions within the range of $0.68-0.85$ indicates the appropriateness of model for simulation of leaf area index in full-irrigation conditions. Considering this range of variations of coefficient of correlation, the amount of coefficient of correlation is significant within the range of 5-1\%, but for Shahriar variety from among the different varieties, the correlation amount was weak but the trend of trait variations has shown well (Table $3)$. Coefficient of correlation $\left(R^{2}\right)$ the measured and simulated functions of varieties in the conditions of stopping irrigation within the range of $0.32-0.75$ indicates that for simulation of leaf area index in this conditions, the model was not successful (except the backcross of Roshan and MV17 varieties) (Table 3). According to the trend of simulated variations of leaf area index in full irrigation and stopping irrigation conditions in Karaj (Fig. 3), the variations range of $d$ coefficient of varieties is respectively within $0.84-0.96$ and $0.76-0.91$ and indicates that the model was successful for predicting the variations trend of leaf area index in both irrigation and drought stress conditions, While, the model was more successful for simulation of LAI in full irrigation conditions than discontinuing the irrigation from the stage of flowering to the end growth stage.

\section{DISCUSSION}

In this study, due to inappropriateness of some environmental factors and losses resulted from abscission of grains, probably due to losses of seed yield due to drop at the time of harvest, the yield of simulated seed has been estimated more than measured amounts. So far CERES-Wheat model has been used in many researches on yield prediction. Dettori et al. (2011) reported that the CERES-Wheat model showed a quite good performance in predicting grain yield and anthesis date. Also in all varieties, the simulated biomass is more than the real amounts of the field. In the experiment by Kiani (2002), the simulated biomass via CERES-Wheat model for wheat varieties in Birjand climatic conditions were more than the real amounts of field. This researcher believes that the main cause non-precise simulation of biomass is due to non-conformity of equations used in CERES-Wheat model for biomass simulation with biomass production conditions in the field.

Coefficient of correlation $\left(\mathrm{R}^{2}\right)$ was showed that the model could not successful simulation of 3 varieties of 5. Probably this is due to excessive high daily temperature during the growth period and consequently leaves are wasted or perhaps due to existing error at 
sampling for leaf are index, because ever measuring the LAI is along with more errors in proportion to the other traits. As was said the model was more successful for simulation of LAI in full irrigation conditions than discontinuing the irrigation from the stage of flowering to the end growth stage. It may be due to nonidentification of varieties in stress conditions because of genetic coefficients applied in both irrigation and drought stress conditions or perhaps other input data to the model (water, whether, soil and field) have not the appropriate accurate and consequently the model could not simulate the stress conditions for some varieties.

\section{CONCLUSION}

The results of CERES-Wheat model assessment in this research indicated that this model in full irrigation and discontinuing the irrigation after flowering stage had appropriate and good accurate, simulation of seed yield and biomass but has simulated the leaf area index well only in full irrigation conditions. Considering the CERES-Wheat model capability for analysis of productive systems of wheat varieties that cause to the economizing time and research costs, this model may be used as an important instrument for state long-term planning. But assessment of yield accuracy prior to its application is such as other models.

\section{ACKNOWLEDGEMENT}

We wish to thank the Karaj Islamic Azad University for its financial support of this study.

\section{REFERENCES}

Ahmadizadeh, M., H. Shahbazi, M. Valizadeh and M. Zaefizadeh, 2011. Genetic diversity of durum wheat landraces using multivariate analysis under normal irrigation and drought stress conditions. Afr. J. Agric. Res., 6: 2294-2302.

Ahmadizadeh, M., M. Valizadeh, M. Zaefizadeh and H. Shahbazi, 2012. Recovery response of durum wheat landraces in drought stress under laboratory and greenhouse conditions. Curr. Res. J. Biol. Sci., 4: $65-70$

Al-Taisan, W.A., 2010. Comparative effects of drought and salt stress on germination and seedling growth of Pennisetum divisum (Gmel.) Henr. Am. J. Applied Sci., 7: 640-646. DOI: 10.3844/ajassp.2010.640.646
Andarzian, B., A.M. Bakhshandeh, M. Bannayan, Y. Emam and G. Fathi et al., 2008. WheatPot: A simple model for spring wheat yield potential using monthly weather data. Biosyst. Eng., 99: 487-495. DOI: 10.1016/j.biosystemseng.2007.12.008

Boote, K.J., M.J. Kropff and P.S. Bindraban, 2001. Physiology and modelling of traits in crop plants: Implications for genetic improvement. Agric. Syst., 70: $\quad 395-420 . \quad$ DOI: $10.1016 /$ S0308$521 \mathrm{X}(01) 00053-1$

Dettori, M., C. Cesaraccio, A. Motroni, D. Spano and P. Duce, 2011. Using CERES-Wheat to simulate durum wheat production and phenology in Southern Sardinia, Italy. Field Crop Res., 120: 179-188. DOI: 10.1016/j.fcr.2010.09.008

Eitzinger, J., M. Stastna, Z. Zalud and M. Dubrousky, 2003. A simulation study of the effect of soil water balance and water stress on winter wheat production under different climate change scenarios. Agric. Water Manage., 61: 195-217. DOI: 10.1016/S0378-3774(03)00024-6

Kiani, A., 2002. CERES-Wheat model evaluation at two different climatic locations in Khorasan province I- Yield prediction. MsC Thesis Ferdosi University, Mashad, Iran.

Knorzer, H., H. Grozinger, S. Graeff-Honninger, K. Hartung and H.P. Piepho et al., 2011. Integrating a simple shading algorithm into CERES-wheat and CERES-maize with particular regard to a changing microclimate within a relay-intercropping system. Field Crops Res., 121: 274-285. DOI: 10.1016/j.fcr.2010.12.016

Reza, E.S.A., M. Gholipour and H.H. Azad, 2005. SBEET: A simple model for simulating sugar beet yield. J. Agric. Sci. Technol., 19: 11-2.

Thorp, K.R., D.J. Hunsaker, A.N. French, J.W. White and T.R. Clarke et al., 2010. Evaluation of the CSM-CROPSIM-CERES-WHEAT model as a tool for crop water Management. Trans. ASABE, 53: 87-102.

Willmott, C.J., 1982. Some comments on the evaluation of model performance. Bull. Am. Meteorol. Soc., 63: 1309-1313. DOI: 10.1175/15200477(1982)063<1309:SCOTEO>2.0.CO;2 